\title{
Fruit tracking, frugivore satiation, and their consequences for seed dispersal
}

\author{
Arndt Hampe
}

\begin{abstract}
Vertebrate frugivore communities are easily satiated by abundant fruit supplies and, contrary to abiotic dispersal agents, typically disperse only part of the available seed pool. This frugivore satiation is likely to be a widespread phenomenon and should be an inXuential predictor of plants' ability to disperse their oVspring to suitable establishment sites; yet it has never been systematically quantiWed. Here I investigate patterns of fruit abundance, frugivore activity and frugivore satiation, and their consequences for seed dispersal in the Xeshy-fruited tree Frangula alnus. Based on constant-eVort seed trapping conducted over 3 years, I assess densities of total and frugivore-consumed seedfall across two spatial (within/between populations) and two temporal (within/between ripening seasons) scales. Furthermore, I examine relationships between fruit abundance and the amount of seeds that are actually dispersed away from fruiting trees. Frugivore activity tightly matched fruit abundance, although some diVerences existed between scales. This marked fruit tracking did not prevent a signiWcant frugivore satiation, however, and only $53 \%$ of the available fruit crops were actually consumed. The extent of satiation varied most at the within-population level, likely due to the territorial behaviour of important frugivore species. In contrast, levels
\end{abstract}

Communicated by Jacqui ShykoV.

\footnotetext{
A. Hampe

INRA, UMR 1202 Biodiversity,

Genes and Communities (BIOGECO),

69 Route d'Arcachon, 33612 Cestas Cedex, France

A. Hampe ( $\&$ )

Integrative Ecology Group, Estación Biológica de Doñana,

CSIC, Apdo. 1056, 41080 Sevilla, Spain

e-mail: arndt@ebd.csic.es
}

of satiation remained remarkably invariable through time, suggesting that frugivores behave as opportunists and closely adjust the composition of their diet to the available food supply. Overall, greater fruit abundance resulted in a higher proportion of seeds falling beneath fruiting trees, but it also helped increase the (absolute) number of seeds dispersed. This study shows that frugivore satiation can be an important phenomenon even when frugivores tightly track fruit abundance. Its negative eVects on recruitment may be attenuated, however, if greater fruit crops help increase population-wide frugivore activity and the amount of seeds being dispersed to suitable establishment sites.

Keywords Crop size · Dispersal limitation · Frugivory · Resource tracking $\cdot$ Seed rain

\section{Introduction}

Frugivory by vertebrates is an important ecological interaction in many environments worldwide (Jordano 2000). Through their fruit selection and foraging patterns, frugivorous animals determine the identity of transported seeds and the sites of delivery. Since seed dispersal limitation is a major constraint for plant recruitment in many systems, frugivore activity can strongly inXuence the demography and genetic structure of plant populations, as well as the composition of plant communities (Jordano and Godoy 2002; Schupp et al. 2002).

Fleshy fruits are typically produced in abundance but very patchily distributed in space and time. Numerous studies have examined how frugivore activity responds to this extensive heterogeneity. Fruit and frugivore abundance often tend to match at local to regional scales, as well as within or among reproductive seasons (Rey 1995; Kinnaird 
et al. 1996; Ortiz-Pulido and Rico-Gray 2000; García et al. 2001; Burns 2002; Moegenburg and Levey 2003; Borgmann et al. 2004; Márquez et al. 2004; Saracco et al. 2004, 2005; Tellería et al. 2005). Such evidence demonstrates that frugivores are able to track fruit resources at a diversity of scales. Other studies Wnd, however, little or no evidence for a systematic resource tracking (Herrera 1998; Tellería and Pérez-Tris 2003, 2007; García and Ortiz-Pulido 2004; Brown and Long 2006), probably because the actual tendency of frugivore populations to track ripe fruit crops is highly dependent of the spatio-temporal scale and the broader ecological context in which the interaction arises.

Both the extent and the scale at which frugivorous seed dispersers track fruit resources should have direct consequences for plants' dispersal success and resulting patterns of regeneration. Contrary to abiotic dispersal agents, animal frugivore communities are easily satiated and typically disperse only a varying proportion of the available seed pool (e.g. Wheelwright 1985; Herrera 1995; García et al. 2001). The strength of this frugivore satiation shapes the competition for seed mobilization within plant populations and communities and may ultimately determine how much eVort plants have to invest to disperse their oVspring to suitable establishment sites. Frugivore satiation is likely to be a widespread phenomenon, and the resulting limited disperser service has potentially wide-ranging consequences for plant regeneration at the population and community level (e.g. Santos and Tellería 1994; Alcántara et al. 1997; Cordeiro and Howe 2001; Burns 2004).

Given the importance of fruit tracking and frugivore satiation for plant dispersal, it seems surprising that their relationship has never been quantiWed in a realistic population context. One likely reason for this lack of evidence is that a combined experimental assessment of fruit tracking and disperser satiation under natural conditions is extremely diYcult, whereas observational approaches require an extensive, replicated sampling involving multiple spatial and/or temporal scales (Kollmann 2000; García and OrtizPulido 2004).

Here, I explore spatio-temporal patterns of fruit production, fruit consumption and frugivore satiation across two spatial and two temporal scales (within/between populations and within/between ripening seasons) for populations of the Xeshy-fruited tree Frangula alnus Miller in southern Spain. Contrary to most previous studies on fruit tracking (but see García et al. 2001), I adopt an approach based on seed rain data obtained through extensive constant-eVort seed trapping conducted at permanent sampling plots. Seed trap data have a series of advantages compared to direct animal observations for exploring frugivore activity. Perhaps most importantly, they allow the quantiWcation of both the abundance of ripe and the proportion of actually consumed seeds within a given space or period. Moreover, seed traps work $24 \mathrm{~h}$ a day and hence give a more complete picture of overall frugivore activity than bird observations. Finally, seed trap records are highly repeatable from one census or year to the other, which greatly aids reducing measurement errors that may confound analyses. These advantages are at the expense of determining the identity of the frugivores involved, which can only be inferred (Jordano and Schupp 2000). But since the aim of this study is to know how an entire disperser guild responds to fruit abundance and how its activity translates into plants' overall seed dispersal success, this drawback seems relatively minor.

SpeciWcally, I address the following questions:

1. How does frugivore activity respond to spatio-temporal variation in fruit abundance?

2. Does frugivore satiation become apparent, and at which spatial and/or temporal scale? ("Satiation" is considered in a strict sense here: frugivore activity should increase with fruit abundance but at a lower pace, which would result in a negative relationship between fruit abundance and the proportion of fruits that are actually consumed.)

3. Which consequences do observed patterns of frugivory and frugivore satiation have for plants' seed dispersal success?

\section{Materials and methods}

Study system

Frangula alnus Miller is a deciduous shrub or small tree growing over much of temperate Europe and western Asia. It is sparsely distributed across mountain ranges of southern Spain and northern Morocco, being a climatic relict restricted to particularly suitable growing sites. Populations occur beside small mountain streams in the understorey of 10- to 15-m-wide riparian forests that extend a few $100 \mathrm{~m}$ to a few kilometres along the stream and are surrounded by Mediterranean sclerophyllous and semideciduous forests (Hampe and Arroyo 2002; Hampe 2004, 2005). F. alnus is common in the dense woody vegetation of these riparian forests dominated by Alnus glutinosa (L.) Gaertn., Rhododendron ponticum ssp. baeticum (Boiss. and Reuter) Hand.Mazz., Viburnum tinus L., Arbutus unedo L., and Quercus canariensis Willd.

Trees produce black berries that usually contain three seeds and ripen from late June until mid-August or September. They are consumed by at least 12 species of the local breeding and postbreeding bird community, although 97\% of the seed dispersal is realized by only three species: Erithacus rubecula L., Sylvia atricapilla L., and Turdus merula 
L. (Hampe 2001). All three species move and forage preferably within the riparian forests, and they tend to concentrate at fruit-rich places when the ripening season of $F$. alnus begins. Their relative importance as fruit consumers reXects their abundance in the study area, which is remarkably stable throughout the fruiting period and apparently also across years (Hampe and Bairlein 2000a). F. alnus is one of the earliest fruiting species in the area, beginning to ripen around 2 weeks before any other species except Rubus ulmifolius Schott (A. Hampe, unpublished data).

\section{Study design}

Field work was carried out in two F. alnus populations, Garganta del Aljibe (hereafter Aljibe) and Garganta del Puerto Oscuro (hereafter Puerto Oscuro), that are situated $5 \mathrm{~km}$ apart in the Aljibe Mountain Range, about $40 \mathrm{~km}$ north-northwest of Gibraltar (36³0'N, 5³5'W; Cádiz Province, Spain). Each population comprises between 1,000 and 1,500 adult trees. Hampe (2004) and Hampe et al. (2008) provide a detailed description of the two gorges, their $F$. alnus populations and the sampling design. Seedfall was monitored along permanent transects. Three replicates were established within each population, with each replicate comprising three line transects (see Fig. 1). Two of them were $60 \mathrm{~m}$ long and ran along the riverbed on each side of the stream, consisting of 16 sampling points. The third transect, including ten points, crossed the centres of the two longitudinal transects. The exact location of sampling points was determined beforehand using a randomization procedure (see Hampe 2004 for details). Sampling replicates were separated by $80-100 \mathrm{~m}$, which was suYcient to ensure that no frugivorous bird territory
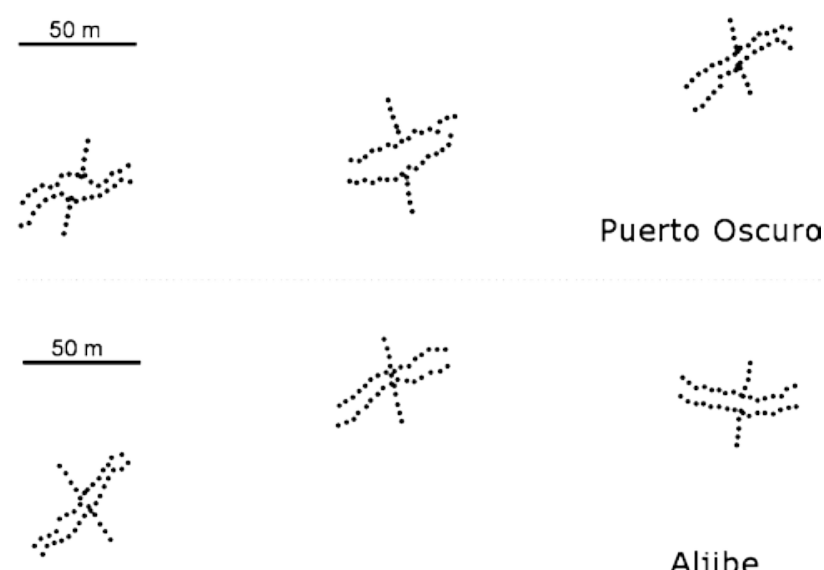

Aljibe

Fig. 1 Spatial arrangement of sampling plots used for seedfall censuses. Each of the two investigated populations contained three sampling transects that were censused 4 times per fruiting season, respectively, through 2000, 2001, and 2002. The seedfall data obtained during each census were pooled within their sampling transects before submitting them to the statistical analyses spanned two diVerent replicates (A. Hampe, unpublished data). Overall, the sampling involved 252 points, 27 (11\%) of which were situated beneath fruiting $F$. alnus canopies (16 in Aljibe, 11 in Puerto Oscuro). A pair of seed traps was placed at each point before the ripening seasons of 2000, 2001 and 2002 to record the seedfall. Traps consisted in drained aluminium dishes ( $30 £ 20 £ 5 \mathrm{~cm}$ ) with an iron mesh to prevent seed predation by mice. Four censuses were carried out at 2-week intervals that covered the complete fruiting season. The Wrst census was always conducted exactly 2 weeks after the Wrst ripe fruit had been detected in the population. All propagules were recorded and classiWed as: (1) unripe fruits (excluded from further analyses), (2) ripe fruits (with the seed number recorded for each fruit), or (3) seeds consumed and either regurgitated or defecated intact by birds. The fourth census recovered only a negligible amount $(0.7 \%)$ of the total seed record and was excluded from further analyses. The seedfall density recorded along transects was highly correlated with the abundance of ripe fruits as inferred from repeated visual estimates of individual tree crops performed at the beginning of each ripening season [Pearson $r=0.94$; see Hampe (2004) for details]; hence, it can be considered a reliable surrogate for overall fruit abundance.

\section{Statistical analysis}

All seed trap records were pooled within their sampling replicates (hereafter referred to as "transects" for simplicity), and the transect-wide average density of total and consumed seedfall was calculated for each census. The Wnal data set thus consisted of 54 whole-transect values for each propagule type. These were distributed: (1) among two populations and three transects per population, and (2) among 3 years and three censuses per year. In other words, sampling was nested with two levels, respectively, both in space and in time. Numerical analyses considered three diVerent variables that represent the three biological phenomena of interest: (1) the density of total seedfall (that is, fruit abundance), (2) the density of seedfall consumed by birds (frugivore activity), and (3) the proportion of the total seedfall that had been consumed (frugivore satiation). The Wrst two variables were log transformed and the latter was logit transformed. All analyses were conducted with $\mathrm{R}$ 2.5.1 (R Development Core Team 2007) using the basic, nlme, ape, and bootstrap packages.

In a Wrst step, I explored the general extent of fruit tracking and frugivore satiation across all sampling units. This was done by an analysis of density dependence, using weighted linear regression with the density of total seedfall as predictor and the density of consumed seedfall as response variable. Within this model, a slope around +1 would suggest that frugivores tightly track fruit abundance 
and are not satiated by the supply, while a slope below +1 would indicate that frugivore satiation is taking place. I included the sample size obtained for each transect and census as weighting variable in order to prevent a disproportionate inXuence of values that were derived from small sample sizes (cf. Crawley 2002). On the other hand, it is well known that relationships of the form $Y$ versus $X+Y$ (here: consumed vs. consumed plus non-consumed seedfall) are commonly subject to spurious correlations and tend to produce inXated $r$-values (Brett 2004). Therefore, I calculated regression slopes and their signiWcance levels from bootstrapped estimates after 5,000 resamplings, as suggested by Brett (2004).

In a second step, I assessed the spatio-temporal variation inherent in the patterns of fruiting, frugivore activity, and satiation. Ripe fruits are typically far from randomly distributed in space and time, and to assess at which scale their abundance varied most was one purpose of this analysis. The second purpose was to examine how tightly, and at which scales, frugivore activity matched this fruit supply. Finally, the interplay between fruit abundance and the response of frugivores determines where and when satiation becomes most evident; therefore analysing its spatiotemporal patterns allows one to infer the relative importance of each factor. Two diVerent approaches were necessary to assess variation in space and in time, respectively. The spatial component was examined by means of a type II ANOVA with transects nested within populations. A variance components analysis quantiWed the level of variation in seed density that was explained by each of the two nesting levels. Data from diVerent censuses were pooled within years for these analyses in order to eliminate superXuous model deviance arising from this source. Variation in time was analysed with linear mixed-eVects models with census (Wxed) as grouping variable and year (random) nested within the former. EVects and their interaction were determined by comparing maximum-likelihood estimates of the full model with those of the corresponding null models without slopes, using $z^{2}$-tests with the number of $d f$ equal to the diVerence in $d f$ between the two models being compared. Again, analyses were conducted on pooled data (in this case pooling transects within populations) instead of the complete dataset. Variance components were estimated according to Venables and Ripley (2002). An additional mixed-model analysis was performed to compare the relative importance of variation in space versus time for all those scales at which signiWcant trends had been detected in the previous two analyses (see "Results").

Finally, I explored how fruit abundance and frugivore activity were related to the actual rate of seed dispersal away from trees. For this, I calculated for each transect and census how many seeds (consumed or not) had been recorded at sampling points situated beneath fruiting trees and how many at points away from them. (A point was considered to be located beneath a tree if it received at least one intact fruit.) These two variables were used to perform weighted linear regressions as described above. Two analyses included the transect-wide total seedfall density as predictor variable and the seedfall density beneath trees, either for total seedfall or for consumed seedfall, as response variable. If disperser satiation takes place, then increasing fruit abundance should result in a greater proportion of seeds that remain undispersed, and the corresponding regression slopes should be steeper than +1 . A third analysis included the transect-wide total seedfall as predictor and the seedfall density recorded away from trees as response variable in order to assess the eVects of fruit abundance on the seed dispersal success of $F$. alnus in absolute terms.

\section{Results}

Through the years 2000-2002 I recorded a total of 3,761 seeds in the two populations, of which 1978 (53\%) had been consumed by frugivorous dispersers. Figure 2 presents relationships between fruit abundance and frugivory

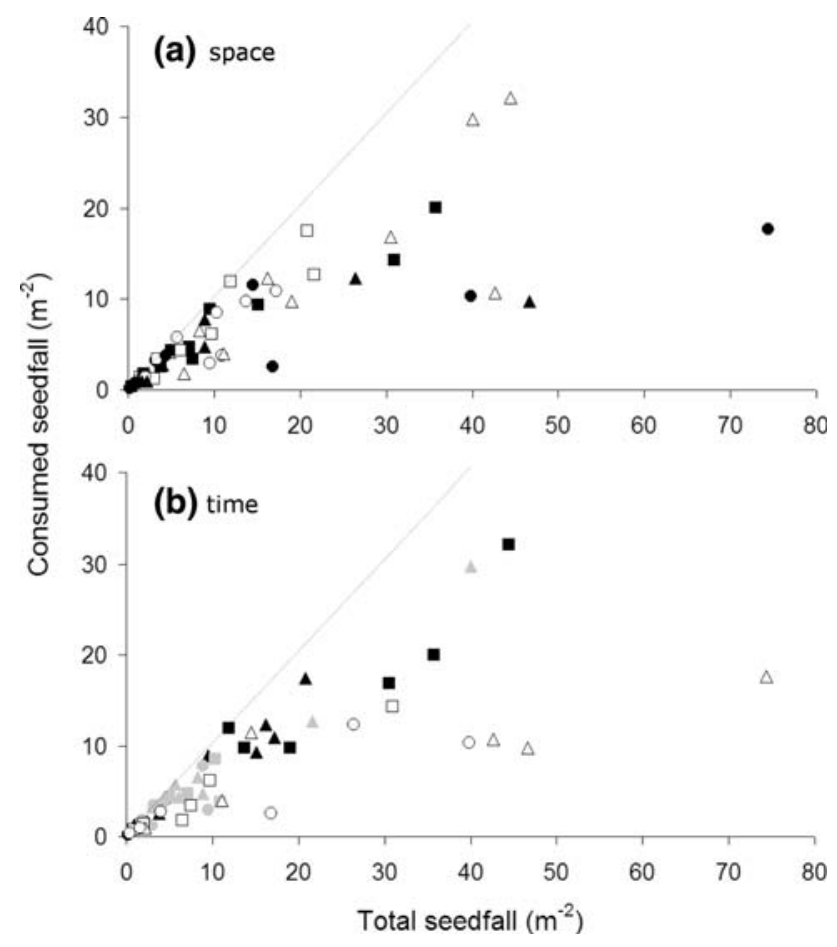

Fig. 2 Relationship between the densities of total and frugivore-consumed seedfall over a spatial position and $\mathbf{b}$ time. Each data point represents the mean value of one transect-wide seed trap census. a The colour of symbols indicates the population (black Aljibe, white Puerto Oscuro), and their shape the transect (square downhill, triangle intermediate, circle uphill). b Data are coded to indicate year collected (black 2000, grey 2001, white 2002), and census (squares Wrst, triangles second, circles third). The broken lines show the regression slope of +1 
Table 1 Spatial variation in fruit production and frugivore activity: results of nested ANOVA and variance components (Var. comp.) analysis. pop. Population

\begin{tabular}{llcrllll}
\hline Response $^{\mathrm{a}}$ & EVect & Var. comp. & $d f$ & SS & MS & $F$ & $P$ \\
\hline \multirow{2}{*}{ Fruiting } & Population & 0.48 & 1 & 4.70 & 4.70 & 9.05 & $\mathbf{0 . 0 1}$ \\
& Transect (pop.) & $<0.001$ & 4 & 1.86 & 0.46 & 0.89 & 0.50 \\
& Residuals & 0.52 & 12 & 6.24 & 0.52 & & \\
Frugivory & Population & 0.30 & 1 & 2.49 & 2.49 & 7.13 & $\mathbf{0 . 0 2}$ \\
& Transect (pop.) & 0.18 & 4 & 2.85 & 0.71 & 2.04 & 0.15 \\
& Residuals & 0.52 & 12 & 4.19 & 0.35 & & \\
Satiation & Population & 0.01 & 1 & 3.83 & 3.83 & 3.60 & 0.08 \\
& Transect (pop.) & 0.44 & 4 & 14.44 & 3.61 & 3.39 & $\mathbf{0 . 0 4}$ \\
& Residuals & 0.55 & 12 & 12.79 & 1.07 & &
\end{tabular}

$P$-values in bold indicate signiWcant eVects

a Response variables refer to the density of total seedfall (Fruiting), the density of seedfall consumed by frugivores (Frugivory) and the proportion of the total seedfall consumed (Satiation)

across space and time and illustrates that frugivore activity responded strongly, and positively, to fruit availability. Accordingly, the weighted linear regression produced a slope of 0.80 (bootstrapped Wrst and third quartile: 0.76 and 0.84). This slope was, however, signiWcantly smaller than 1 ( $P<0.001$ according to randomization with $n=5,000$ resamplings), thus clearly indicating satiation of the frugivore community.

Table 1 summarizes the principal scales of spatial variation in fruiting, frugivore activity and satiation (see also Fig. 2). Fruit abundance diVered signiWcantly between populations but not among transects within the same population. Frugivore activity followed this pattern of fruit abundance, although the matching was not overly tight. The extent of disperser satiation showed a contrasting pattern, however, varying less than the other two parameters at the between-population level but markedly more among transects within each population (see variance components given in Table 1). Somewhat diVerent patterns became evident for the temporal component (Table 2, see also Fig. 2).
Fruit abundance changed signiWcantly through the course of the ripening season but not among years. Its dynamics were very tightly matched by frugivore activity. As a consequence, the extent of disperser satiation was virtually independent of the temporal scale examined: less than $5 \%$

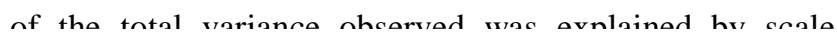
eVects (Table 2)

Thus. signiWrant variation was detected within vears (fruiting and frugivorv) as well as hoth within (frugivorv) and between (fruiting) pobulations. When these sDatial and temooral scales were integrated within a single analvsis. only the time eVect remained signiWcant (Table 3). It should, however, be noted that space eVects, though not signiWcant, accounted likewise for a non-negligible amount of the overall variation observed (see variance components in Table 3); in other words, the spatial patterns observed in the previous analysis were not only a simple secondary eVect of temporal patters. Once again, levels of frugivore satiation did not display signiWcant variation across the spatial and temporal scales examined.

The proportion of seedfall that landed beneath fruiting trees was positively related to overall fruit abundance, as predicted under frugivore satiation, although the relationship was not overly tight (Table 4). On the contrary, the proportion of consumed seedfall deposited beneath trees did not increase with fruit abundance (and hence frugivore activity). Finally, greater fruit abundance resulted in a higher absolute amount of seeds being dispersed away from trees (Table 4); the slope of 0.49 indicates that populations had to produce approximately two additional seeds in order to disperse one of them.

\section{Discussion}

This study aimed at exploring three questions: Do frugivores track ripe fruit abundance? Are they satiated by the fruit supply? Does this satiation have notable consequences for plants' seed dispersal? All three questions can be answered positively.
Table 2 Temporal variation in fruit production and frugivore activity: results of linear mixedmodel analysis. Adj. Adjusted, $2 L L \log$ likelihood

\begin{tabular}{llcccccc}
\hline Response $^{\mathrm{a}}$ & EVect & Var. comp. & Adj. mean § SE & $d f$ & $F$ & 2LL & $P$ \\
\hline Fruiting & Census & 0.39 & $\mathbf{i} 0.59$ § 0.27 & 1,14 & 4.77 & & $\mathbf{0 . 0 4}$ \\
& Year (census) & $<0.001$ & & & & 0.90 & 0.64 \\
& Residuals & 0.61 & & & & & \\
\multirow{5}{*}{ Frugivory } & Census & 0.47 & $\mathbf{i} 0.55 \S 0.23$ & 1,14 & 5.80 & & $\mathbf{0 . 0 3}$ \\
& Year (census) & 0.07 & & & & 1.79 & 0.41 \\
& Residuals & 0.46 & & & & & \\
\multirow{5}{*}{ Satiation } & Census & $<0.001$ & 0.12 § 0.20 & 1,14 & 0.35 & & 0.56 \\
& Year (census) & 0.04 & & & & 0.14 & 0.93 \\
& Residuals & 0.96 & & & & & \\
\hline
\end{tabular}


Table 3 Relationship between spatial and temporal variation in fruit production and frugivore activity: results of linear mixedmodel analysis. See Tables 1 and 2 for abbreviations

\begin{tabular}{|c|c|c|c|c|c|c|c|}
\hline Response $^{\mathrm{a}}$ & EVect & Var. comp. & Adj. mean § SE & $d f$ & $F$ & $2 \mathrm{LL}$ & $P$ \\
\hline \multirow[t]{3}{*}{ Fruiting } & Census & 0.18 & i 0.61 \$ 0.17 & 1,51 & 8.55 & & 0.005 \\
\hline & Population (census) & 0.25 & & & & 0.81 & 0.67 \\
\hline & Residuals & 0.57 & & & & & \\
\hline \multirow[t]{3}{*}{ Frugivory } & Census & 0.30 & i $0.61 \S 0.17$ & 1,51 & 12.72 & & 0.0008 \\
\hline & Population (census) & 0.15 & & & & 1.16 & 0.56 \\
\hline & Residuals & 0.55 & & & & & \\
\hline \multirow[t]{3}{*}{ Satiation } & Census & $<0.001$ & i 0.27 \$ 0.20 & 1,51 & 1.85 & & 0.18 \\
\hline & Population (census) & 0.04 & & & & 1.20 & 0.54 \\
\hline & Residuals & 0.96 & & & & & \\
\hline \multirow[t]{3}{*}{ Fruiting } & Census & 0.28 & i $0.51 \S 0.17$ & 1,47 & 9.08 & & 0.004 \\
\hline & Transect (census) & 0.11 & & & & 0.29 & 0.85 \\
\hline & Residuals & 0.61 & & & & & \\
\hline \multirow[t]{3}{*}{ Frugivory } & Census & 0.35 & i $0.54 \$ 0.14$ & 1,47 & 14.81 & & 0.0004 \\
\hline & Transect (census) & 0.17 & & & & 0.92 & 0.63 \\
\hline & Residuals & 0.48 & & & & & \\
\hline \multirow[t]{3}{*}{ Satiation } & Census & $<0.001$ & i 0.27 \$ 0.18 & 1,47 & 2.26 & & 0.13 \\
\hline & Transect (census) & 0.20 & & & & 2.26 & 0.32 \\
\hline & Residuals & 0.80 & & & & & \\
\hline
\end{tabular}

Table 4 Relationship between the average density of total seedfall across sampling transects and the rate of actual seed dispersal away from fruiting trees

\begin{tabular}{lc}
\hline Response variable & Slope $^{\mathrm{a}}$ \\
\hline Total seedfall beneath trees & $1.28(1.12 ; 1.36)$ \\
Consumed seedfall beneath trees & $1.08(0.90 ; 1.31)$ \\
Consumed seedfall away from trees & $0.49(0.27 ; 0.68)$
\end{tabular}

${ }^{\text {a }}$ Bootstrapped slope estimates with $99 \%$ percentiles in parentheses

Fruit abundance and frugivore behaviour

Frugivore activity clearly responded to fruit abundance across all spatial and temporal scales investigated: the more fruits were available in a given area or period the more were actually consumed. Frugivore activity increased, however, at a lower pace than the fruit supply (slope $=0.80$ ), which indicated a notable satiation of the frugivore community. Its extent diVered across the investigated dimensions and scales, and these diVerences provide some closer insights into the components of frugivore behaviour that trigger birds' responses to spatio-temporal patterns of fruit availability. For this purpose, it is helpful to recall the composition and situation of the local frugivore avifauna at the time when $F$. alnus fruits become available (Hampe and Bairlein 2000a, 2000b; Hampe 2001): by far most fruits are consumed and dispersed by three species of the local breeding bird community, whose behaviour diVers greatly. $S$. atricapilla and T. merula still form groups composed of parents and recently Xedged chicks that usually have com- paratively small home ranges. They regularly enter fruiting trees together and tend to stay longer and ingest more fruits per foraging visit than E. rubecula. This species is already rearing a second brood when $F$. alnus fruits mature, and the young of the Wrst brood have been expulsed from the parents' territories. On postnatal dispersal, these highly mobile birds perform about half of all frugivore visits to $F$. alnus, and they might in fact rely to a large extent on this easily accessible food source during the Wrst weeks of their independence.

The described situation and behaviour of $F$. alnus' frugivore guild helps explain the observed spatio-temporal patterns of frugivore satiation. S. atricapilla and T. merula are important dispersers of $F$. alnus, and since not all sampling transects harboured families of these species, it is of little surprise that frugivore satiation became markedly more evident in some transects than in others, even though fruit abundance did not vary at this scale (see Table 1). These results suggest moreover that the high site Wdelity of $S$. atricapilla and T. merula families prevents them from tracking fruit abundance across transects (see also Tellería and Pérez-Tris 2007 for S. atricapilla). This is in fact rarely necessary, because $F$. alnus is so common in the area that each bird territory usually includes some fruiting trees. Hence, S. atricapilla and T. merula would track ripe $F$. alnus fruits at an even smaller spatial scale than the length of sampling transects $(60 \mathrm{~m})$. On the other hand, both fruit abundance and frugivore activity diVered signiWcantly between populations, and they were so tightly linked that the extent of frugivore satiation did not vary at this scale. This pattern, inverse to that observed at the transect scale, 
might indicate that fruit tracking also takes place to some extent at this large spatial scale. Such behaviour at a large local to regional scale has commonly been documented for migrant and wintering birds (see Rey 1995; Márquez et al. 2004; Tellería and Pérez-Tris 2003, for southern Spanish examples). In the present case, it might be due to movements of young $E$. rubecula during their postnatal dispersal (see Vega-Rivera et al. 1998; White et al. 2005, for similar cases of fruit tracking by juvenile birds).

On the other hand, the temporal match between fruit abundance and frugivore activity was surprisingly tight. This suggests in the Wrst place that frugivores behave as opportunists and closely adjust the composition of their diet to the available food supply. On the contrary, frugivore abundance does not explain the observed decline in (absolute) fruit consumption that paralleled the successive decline in ripe fruit abundance, because it tends to remain largely invariable throughout the ripening period of $F$. alnus (Hampe and Bairlein 2000a). Perhaps even more remarkable was the stability of the disperser service from one year to the next, although this may be explained by the fact that $F$. alnus is dispersed by a comparatively stable breeding bird community, which remains year-round in the area (Tellería and Pérez-Tris 2004, 2007) and is likely to experience much less among-year variation in abundance than communities of migrants or birds wintering in the region (Herrera 1998; García et al. 2001; Tellería et al. 2005). It seems noteworthy that this great stability among years is not only reXected in the extent of frugivory described here, but also in the spatial distributions of seed rain recorded throughout the study period (Hampe et al. 2008). In conclusion, the particular behaviour of the frugivore community rendered disperser satiation a scale-independent phenomenon as far as time was concerned.

\section{Consequences for seed dispersal}

The investigated $F$. alnus populations are a special case in the sense that they do not rely anymore on birds as their principal seed dispersers (Hampe 2004). In most Xeshyfruited plants, however, non-dispersed seeds almost always fail to establish and reach adulthood beneath their mothers. Consequently, the activity of frugivorous seed dispersers and the extent of satiation are potentially of critical importance for patterns of plant regeneration (cf. Jordano and Godoy 2002; Muller-Landau et al. 2002; Schupp et al. 2002).

The overall fruit supply oVered by F. alnus was closely linked to both the absolute number and the proportion of seeds that landed beneath fruiting canopies. In other words, the more seeds were produced the more were presumably lost for recruitment due to disperser satiation. However, a greater fruit supply also generated greater activity of frugi- vores, which dispersed more seeds away from the mother trees. It has often been speculated which factor should be more decisive for the reproductive success of Xeshy-fruited plants: the absolute amount of seeds dispersed or the eVort spent per dispersed seed (e.g. Muller-Landau et al. 2002; Wright et al. 2005, and references therein). In the present case, the additional eVort needed is not excessive: The observed regression slope of 0.49 indicates that populations have to produce two additional seeds in order to disperse one of them. This is indeed a minor investment given that survival rates of non-dispersed seeds are usually orders of magnitudes lower than those of dispersed seeds.

Numerous studies have tried to explore, from a diversity of viewpoints, which crop size represents an optimal compromise between frugivore attraction and propagule loss (e.g. Howe and Estabrook 1977; Jordano 1987; Herrera et al. 1998; Ortiz-Pulido and Rico-Gray 2000). However, few have attempted to combine fruit crop and seed rain data (but see Alcántara et al. 2000), and none has to my knowledge assessed relationships between the actual proportion of consumed seeds and plants' dispersal success. As a consequence, current models do not explicitly consider this factor; it therefore seems noteworthy that the phenomenon of frugivore satiation shows a series of parallels with the eVect of geitonogamy in Xowering plants (de Jong et al. 1993). The well-developed theoretical framework of this latter Weld of research might provide readily applicable tools to explore consequences of the interplay between fruit production, frugivore activity and satiation for seed dispersal.

\section{Disperser satiation: future research needs}

This study quantiWes for the Wrst time the phenomenon of disperser satiation and its consequences for seed dispersal. One noteworthy result is that even tight fruit tracking by frugivores did not prevent about half of the seeds remaining undispersed. It seems likely that disperser satiation is widespread in natural populations and that it has ample consequences, including aspects of population and community ecology (Herrera 1995; García et al. 2001; Burns 2002, 2004; Wright et al. 2005), conservation (Santos and Tellería 1994; Alcántara et al. 1997; Cordeiro and Howe 2001) and evolutionary biology (Herrera et al. 1998; Burns 2004). Future research should aim at exploring how prevalent the phenomenon is in diVerent environments and to which extent it depends on the spatio-temporal dynamics and diversity of the involved plant and animal communities. On the other hand, the biological features that determine the extent of satiation and its consequences should also be explored. These include plant characters (such as ripening season, fecundity, fruit size and persistence, etc.) and frugivore characters (such as fruit preferences, nutri- 
tional status, or mobility) as well as parameters of the landscape context (fruiting plant density, occurrence of other fruiting species, etc.). Finally, only investigating the delayed eVects of frugivore satiation on recruitment will allow a thorough evaluation of the eVects of frugivore satiation on patterns of regeneration in natural plant populations and communities.

Acknowledgements I thank the sta $\mathrm{V}$ of the Los Alcornocales Natural Park for the permission and logistic support I received during Weldwork. Enrico Rezende and Pedro Jordano provided valuable help with some of the statistical analyses and thoughtful comments from Luc Barbaro, Kevin Burns, Jacqui ShykoV, and an anonymous reviewer helped improve a previous version of the text. Fieldwork was funded by the Spanish Ministry of Science and Technology (grants PB981144, BOS2002-01162 and REN2003-00273) and Wnal elaboration by a Marie Curie postdoctoral fellowship of the European Union (grant MEIF-CT-2006-025383). Thus study was conducted in compliance with Spanish legislation.

\section{References}

Alcántara JM, Rey PJ, Valera F, Sánchez-Lafuente AM, Gutiérrez JE (1997) Habitat alteration and plant intra-speciWc competition for seed dispersers. An example with Olea europaea var. sylvestris. Oikos 79:291-300

Alcántara JM, Rey PJ, Valera F, Sánchez-Lafuente AM (2000) Factors shaping the seedfall pattern of a bird-dispersed plant. Ecology 81:1937-1950

Borgmann KL, Pearson SF, Levey DJ, Greenberg CH (2004) Wintering yellow-rumped warblers (Dendroica coronata) track manipulated abundance of Myrica cerifera fruits. Auk 121:74-87

Brett MT (2004) When is a correlation between non-independent variables "spurious"? Oikos 105:647-656

Brown DR, Long JA (2006) Experimental fruit removal does not aVect territory structure of wintering Hermit Thrushes. J Field Ornithol 77:404-408

Burns KC (2002) Seed dispersal facilitation and geographic consistency in bird-fruit abundance patterns. Glob Ecol Biogeogr 11:253-259

Burns KC (2004) Scale and macroecological patterns in seed dispersal mutualisms. Glob Ecol Biogeogr 13:289-293

Cordeiro NJ, Howe HF (2001) Low recruitment in trees dispersed by animals in African forest fragments. Conserv Biol 15:1733-1741

Crawley MJ (2002) Statistical computing: an introduction to data analysis using S-Plus. Wiley, Chichester

de Jong TJ, Waser NM, Klinkhamer PGL (1993) Geitonogamy: the neglected side of selWng. Trends Ecol Evol 8:321-325

García D, Ortiz-Pulido R (2004) Patterns of resource tracking by avian frugivores at multiple spatial scales: two case studies on discordance among scales. Ecography 27:187-196

García D, Zamora R, Gómez JM, Hódar JA (2001) Frugivory at Juniperus communis depends more on population characteristics than on individual attributes. J Ecol 89:639-647

Hampe A (2001) The role of fruit diet within a temperate breeding bird community in southern Spain. Bird Study 48:116-123

Hampe A (2004) Extensive hydrochory uncouples spatiotemporal patterns of seedfall and seedling recruitment in a bird-dispersed riparian tree. J Ecol 92:797-807

Hampe A (2005) Fecundity limits in Frangula alnus (Rhamnaceae) relict populations at the species' southern range margin. Oecologia 143:377-386
Hampe A, Arroyo J (2002) Recruitment and regeneration in populations of an endangered South Iberian Tertiary relict tree. Biol Conserv 107:263-271

Hampe A, Bairlein F (2000a) ModiWed dispersal-related traits in disjunct populations of bird-dispersed Frangula alnus (Rhamnaceae): a result of its Quaternary distribution shifts? Ecography 23:603-613

Hampe A, Bairlein F (2000b) Nahrungssuche und Vergesellschaftung frugivorer Zug- und Brutvögel. J Ornithol 141:300-308

Hampe A, Garcia-Castaño JL, Schupp EW, Jordano P (2008) Spatiotemporal dynamics and local hotspots of initial recruitment in vertebrate-dispersed trees. J Ecol 96:000-000

Herrera CM (1995) Plant-vertebrate seed dispersal systems in the Mediterranean: ecological, evolutionary, and historical determinants. Annu Rev Ecol Syst 26:705-727

Herrera CM (1998) Long-term dynamics of Mediterranean frugivorous birds and Xeshy fruits: a 12-year study. Ecol Monogr 68:511-538

Herrera CM, Jordano P, Guitián J, Traveset A (1998) Annual variability in seed production by woody plants and the masting concept: reassessment of principles and relationship to pollination and seed dispersal. Am Nat 152:576-594

Howe HF, Estabrook GF (1977) On intraspeciWc competition for avian dispersers in tropical trees. Am Nat 11:817-832

Jordano P (1987) Avian fruit removal: eVects of fruit variation, crop size, and insect damage. Ecology 68:1711-1723

Jordano P (2000) Fruits and frugivory. In: Fenner M (ed) Seeds-the ecology of regeneration in plant communities, 2nd edn. CAB International, Wallingford, pp 125-165

Jordano P, Godoy JA (2002) Frugivore-generated seed shadows: a landscape view of demographic and genetic eVects. In: Levey D, Silva WR, Galetti M (eds) Seed dispersal and frugivory: ecology, evolution and conservation. CAB International, Wallingford, pp 305-321

Jordano P, Schupp EW (2000) Seed disperser eVectiveness: the quantity component and patterns of seed rain for Prunus mahaleb. Ecol Monogr 70:591-615

Kinnaird MF, OBrien TG, Suryadi S (1996) Population Xuctuation in Sulawesi red-knobbed hornbills: tracking Wgs in space and time. Auk 113:431-440

Kollmann J (2000) Dispersal of Xeshy-fruited species: a matter of spatial scale? Perspect Plant Ecol 3:29-51

Márquez AL, Real R, Vargas JM (2004) Dependence of broad-scale geographical variation in Xeshy-fruited plant species richness on disperser bird species richness. Glob Ecol Biogeogr 13:295-304

Moegenburg SM, Levey DJ (2003) Do frugivores respond to fruit harvest? An experimental study of short-term responses. Ecology 84:2600-2612

Muller-Landau HC, Wright SJ, Calderón O, Hubbell SP, Foster RB (2002) Assessing recruitment limitation: concepts, methods and case-studies from a tropical forest. In: Levey DJ, Silva WR, Galetti $M$ (eds) Seed dispersal and frugivory: ecology, evolution and conservation. CAB International, Wallingford, pp 35-53

Ortiz-Pulido R, Rico-Gray V (2000) The eVect of spatio-temporal variation in understanding the fruit crop size hypothesis. Oikos 91:523-527

R Development Core Team (2007) R: a language and environment for statistical computing. http://www.R-project.org

Rey PJ (1995) Spatio-temporal variation in fruit and frugivorous bird abundance in olive orchards. Ecology 76:1625-1635

Santos T, Tellería JL (1994) InXuence of forest fragmentation on seed consumption and dispersal of Spanish Juniper Juniperus thurifera. Biol Conserv 70:129-134

Saracco JF, Collazo JA, Groom JM (2004) How do frugivores track resources? Insights from spatial analyses of bird foraging in a tropical forest. Oecologia 139:235-245 
Saracco JF, Collazo JA, Groom MJ, Carlo TA (2005) Crop size and fruit neighborhood eVects on bird visitation to fruiting ScheZera morototoni trees in Puerto Rico. Biotropica 37:81-87

Schupp EW, Milleron T, Russo SE (2002) Dissemination limitation and the origin and maintenance of species-rich tropical forests. In: Levey DJ, Silva WR, Galetti M (eds) Seed dispersal and frugivory: ecology, evolution and conservation. CAB International, Wallingford, pp 19-33

Tellería JL, Pérez-Tris J (2003) Seasonal distribution of a migratory bird: eVects of local and regional resource tracking. J Biogeogr 30:1583-1591

Tellería JL, Pérez-Tris J (2004) Consequences of the settlement of migrant European Robins Erithacus rubecula in wintering habitats occupied by conspeciWc residents. Ibis 146:258-268

Tellería JL, Pérez-Tris J (2007) Habitat eVects on resource tracking ability: do wintering blackcaps Sylvia atricapilla track fruit availability? Ibis 149:18-25
Tellería JL, Ramírez A, Pérez-Tris J (2005) Conservation of seed-dispersing migrant birds in Mediterranean habitats: shedding light on patterns to preserve processes. Biol Conserv 124:493-502

Vega-Rivera JH, Rappole JH, McShea WJ, Haas CA (1998) Wood Thrush postXedging movements and habitat use in northern Virginia. Condor 100:69-78

Venables WN, Ripley BD (2002) Modern applied statistics with S, 4th edn. Springer, New York

Wheelwright NT (1985) Competition for dispersers, and the timing of Xowering and fruiting in a guild of tropical trees. Oikos 44:465477

White JD, Gardali T, Thompson FR, Faaborg J (2005) Resource selection by juvenile Swainson's thrushes during the postXedging period. Condor 107:388-401

Wright SJ, Muller-Landau HC, Calderón O, Hernández A (2005) Annual and spatial variation in seedfall and seedling recruitment in a neotropical forest. Ecology 86:848-860 